\title{
RESEARCH AND USE OF MECHANICAL STRUCTURE FATIGUE DAMAGE USING MEMBERSHIP FUNCTION
}

\author{
Haihui $W u^{1}$ \\ ${ }^{1}$ Ankang University, Shaanxi, China \\ Email: wuhaihuishxi2011@yeah.net
}

\begin{abstract}
Objective: Through the establishment of the rule of fuzzy linear cumulative damage (Miner) of membership function, the fatigue life of components can be predicted or estimated. At the same time, material optimization and process optimization are carried out to provide theoretical basis for the development of anti-fatigue materials. Method: Firstly, based on the defects of traditional Miner's law, a modified Miner's law is proposed. Through experiments, the feasibility of the revised model is verified, and on the basis of it, aiming at its shortcomings, a fuzzy Miner rule is proposed. There are five kinds of membership functions of fuzzy theory: linear type, square root type, Haibach model (Haibach type), parabolic type and normal type. Results: The prediction error of the revised model is obviously smaller than that of the traditional model, and the error is about $10 \%$. The error of parabolic membership function is further reduced to about $9 \%$. Conclusion: In this study, based on the traditional Miner rule of structural fatigue life prediction, the proposed model and method are proved to be feasible and accurate through experimental comparison, but the existing errors should also be fully considered in practical application, so as to avoid huge damage to the structure.
\end{abstract}

Keywords: Membership Function; Fuzzy Miner Rule; Mechanical Structure; Fatigue Life; Alloy Steel for Gear.

\section{Introduction}

The mechanical structure has been in service for a long time under the condition of high load and high speed, and each component bears the effect of complex alternating load. Fatigue is the main failure mode. Therefore, the study of fatigue mechanism is of great practical value in engineering. On the one hand, it can solve the problem of fixed life, that is, it can predict or estimate the fatigue life of components, so as to prevent catastrophic damage of structures and avoid huge losses. On the other hand, to solve the problem of life extension, we can optimize the material and process, so as to extend the fatigue life of parts and provide theoretical basis for the subsequent development of new anti-fatigue materials [1].

The theory of fatigue cumulative damage is the key problem of fatigue life prediction. It is a related theory to study how the fatigue damage will accumulate and develop when the variable amplitude load acts on the material, and to what extent will the material develop fatigue failure [2].

Therefore, the core problem of life prediction research is fatigue damage caused by fatigue damage accumulation. It is particularly important to resist fatigue design and fatigue reliability, which is highly valued by many experts and scholars. Through a large number of experiments and theoretical research, many scholars have put forward many kinds of fatigue cumulative damage theories and methods, which are divided into two categories: linear and nonlinear fatigue damage cumulative models [3]. However, most of these methods are deterministic theories. However, the formation of fatigue damage is often affected by material characteristics, load history, structural geometry size and use environment, and these factors have considerable uncertainty due to individual differences.

Therefore, how to establish a fatigue damage accumulation mechanism that can correctly reflect the influence of various uncertain factors in fatigue failure is the hot spot of structural fatigue life prediction [4].

In this study, based on the problems of traditional fatigue damage model, an improved cumulative damage model is proposed.

In this model, the influence of loading sequence and load interaction is considered. Through model evaluation and comparative analysis, it shows that Miner's rule is widely used in engineering.

In view of the shortcomings of traditional Miner's rule, the influence of load interaction and load sequence on fatigue life prediction is quantitatively considered in Miner's rule.

A fuzzy Miner's rule based on membership function considering load sequence is proposed. 


\section{Methods}

\subsection{Modified nonlinear fatigue damage accumulation model}

The traditional linear damage theory has defects. The iterative calculation of nonlinear theory is too long and the parameters are not easy to be determined. The boundary point between fatigue crack initiation and crack growth of bilinear theory is not easy to be determined, so people are urged to seek better methods to overcome the shortcomings of the above methods [5].

According to the $\mathrm{S}-\mathrm{N}$ curve, in this study, based on Manson-Halford damage curve method, considering the loading sequence of the load and the

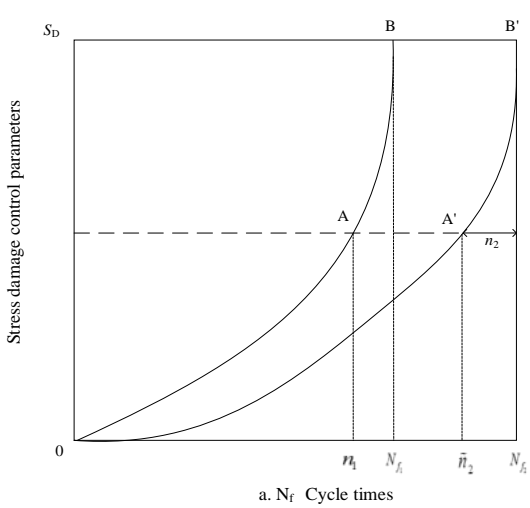

interaction of the load with the index $\mathrm{d}$ in the CartenDolan model, the fatigue damage parameter $S_{D}$ of stress control is proposed as [6]:

$$
S_{D}=N_{f}^{\beta} S^{m}
$$

In the equation, $\beta=\frac{\mathrm{n}}{N_{f}}$ is the cycle ratio. First, two-stage loading is considered.

The first level load acts for $n_{1}$ times and the second level load acts for $n_{2}$ times until fatigue failure occurs, as shown in Figure 1.

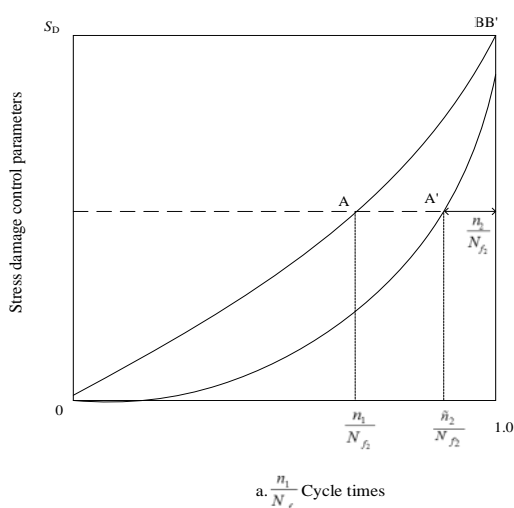

Figure 1: Accumulation of fatigue damage parameters under two-stage loading

According to the equivalence of fatigue damage parameters, the damage caused by cycle $n_{1}$ under the first level load $S_{1}$ shall be equal to the damage caused by cycle $\widetilde{\boldsymbol{x}}_{2}$ under the second level load $S_{2}$ [7], that is:

$$
S_{D_{1}}=S_{D_{2}}=S_{2}^{m} \mathrm{~N}_{f_{2}}^{\beta_{O}^{O}}
$$

Under the action of load $S_{2}$, the damage parameter $S_{D_{1-2}}$ when fatigue failure is reached is:

$S_{D_{1-2}}=S_{2}^{m} \cdot N_{f_{2}}^{\beta_{1}+\beta_{2}}=S_{2}^{m} \cdot N_{f_{2}}^{\frac{\left(f_{2} f_{2}+n_{2}\right)}{N_{f_{2}}}}$

When the damage parameter reaches the critical value $C$, according to equations 2 and 3 , it can be obtained that:

$$
S_{D_{1-2}}=S_{2}^{m} \cdot N_{f_{2}}^{\frac{\left(f_{f_{2}}+\mathrm{n}_{2}\right)}{N_{f_{2}}}}=S_{1}^{m} \cdot N_{f_{1}}^{\beta_{1}} \cdot N_{f_{2}}^{\beta_{2}^{o}}=C
$$
that:

$$
N_{f_{1}}^{\beta_{1}} \cdot N_{f_{2}}^{\beta_{2}^{\circ}}=\frac{C}{S_{1}^{m}}=N_{f_{1}}
$$

After taking logarithm of both sides of the above equation, it can be obtained that:

$$
\beta_{1} \ln N_{f_{1}}+\beta_{2}^{o} \ln N_{f_{1}}=\ln N_{f_{1}}
$$

Therefore, under the action of two-stage load, according to equation 1 and equation 6 , the cumulative amount of fatigue damage is:

$$
D=\beta_{2}^{o}+\beta_{2}=\left(1-\beta_{1}\right) \frac{\ln N_{f_{1}}}{\ln N_{f_{2}}}+\beta_{2}
$$

Similarly, the loading for the third stage load is as shown in Figure 2.

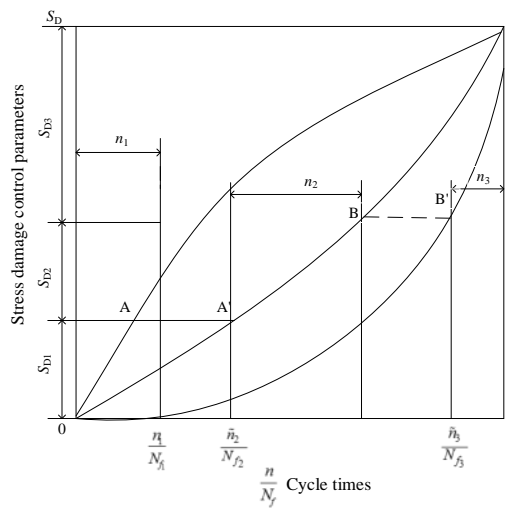

Figure 2: Accumulation of fatigue damage parameters under third-order loading

According to the damage equivalence, the damage caused by the joint action of the first level load $S_{1}$ and the second level load $S_{2}$ should be 
transformed into the damage parameter caused by the third level load $S_{3}$ cycle $\mathscr{R}_{3}$ times.

The fatigue damage accumulation under the third level load is as follows:

$$
\begin{aligned}
D= & \beta_{3}^{o}+\beta_{3} \\
= & 1-\left\{1-\left(1-\beta_{1}\right) \frac{\ln N_{f_{1}}}{\ln N_{f_{2}}}+\beta_{2}\right\} \frac{\ln N_{f_{1}}}{\ln N_{f_{3}}}+ \\
& \frac{n_{3}}{N_{f_{3}}}
\end{aligned}
$$

By analogy, the fatigue damage accumulation under multi-stage loading is:

$$
\begin{aligned}
& D= \beta_{n-1}^{o}+\beta_{n} \\
&\left.1-\left(\begin{array}{l}
1- \\
\left(1-\beta_{1}\right) \\
\frac{\ln N_{f_{1}}}{\ln N_{f_{2}}}
\end{array}\right)\right) \\
&= 1-\left\{\begin{array}{l}
\ln N_{f_{2}} \\
\ln N_{f_{3}} \\
+\frac{n_{2}}{N_{f_{2}}}
\end{array}\right\} \\
& \frac{\ln N_{f_{2}}}{\ln N_{f_{3}}}+\frac{n_{i}}{N_{f_{i}}}
\end{aligned}
$$

The above equation is the nonlinear fatigue damage accumulation model of the improved damage curve method. In this model, not only the influence of load sequence on life prediction, but also the influence of load interaction on life prediction are considered. The parameters of the model are small, so it can be easily applied to practical engineering [8].

\subsection{Miner's rule based on fuzzy theory}

In 1965, Professor Zadeh, an American cybernetic expert, founded fuzzy mathematics. Before, people could only deal with the binary logic problem of "either or" with mathematics, while fuzzy mathematics solved the problem of "both this and that", making up the defect of binary logic before [9]. In the prediction of structural fatigue life, fatigue failure is totally different from static failure, which has essential difference. Under the continuous action of cyclic stress, the damage is accumulating, which leads to fatigue failure, and then leads to the failure of structural elements. This process is a gradual process, from intact state to failure state. The transition states in the middle are interpenetrating and interrelated.

These transition states belong to the fuzzy state of "this and that" and are in the two of "intact" and "invalid" [10]. The traditional fatigue life prediction method defines the fatigue limit as a certain value, and considers that any stress lower than the fatigue limit will not cause damage to the structural components. It is obviously not in line with the objective facts that "both this and that" is used to determine whether there is damage. During the service process of components or materials, the fatigue limit of mechanical components cannot be "determined value" because of factors such as stress conditions, loading sequence, external structure size, processing quality, surface integrity, etc. Since the fatigue limit value is uncertain, it will inevitably lead to "fuzziness" of damage.

Generally, Miner's rule is based on the fatigue limit of the component to judge whether the stress will cause damage to the component, but the fatigue limit of the component is affected by many external uncertain factors, which is a "uncertain" quantity. Therefore, this uncertainty factor is also transmitted to the next link, leading to the uncertainty of whether the stress causes fatigue damage to the components [11]. In the above content, it has been discussed that the order of loading is an important factor of fatigue life. When the high-low load is applied to the mechanical components, the fatigue limit of the mechanical structure will change under the action of high load, and its value will decrease. In this case, if the traditional miner rule is applied to estimate the fatigue life, the estimated result is more dangerous than the actual situation. When the loading sequence of low-high load is adopted, the load can strengthen the fatigue limit, which will improve the fatigue limit to a certain extent. At this time, the traditional Miner rule is used to calculate the fatigue life, and the estimated result is more conservative than the actual situation. Through the above analysis, the cumulative damage value of mechanical components is different under different loading sequence, which is an interval variable [12].

If the fatigue limit of the component is $S_{R}$, under the action of high-low load, the fuzzy lower bound of the fatigue limit is $\left(\mathrm{s}_{\mathrm{R}}\right)_{\mathrm{H}-\mathrm{L}}$. Under the action of lowhigh load, the fuzzy upper bound of the fatigue limit is $\begin{aligned}\left(\mathrm{s}_{\mathrm{R}}\right)_{L-H}: & \left\{\begin{array}{l}\left(\mathrm{s}_{\mathrm{R}}\right)_{\mathrm{H}-\mathrm{L}}=s_{R}-\Delta s_{-} \\ \left(\mathrm{s}_{\mathrm{R}}\right)_{L-H}=s_{R}+\Delta s_{+}\end{array}\right.\end{aligned}$

In the equation, $\left(\mathrm{s}_{\mathrm{R}}\right)_{\mathrm{H}-\mathrm{L}}$ represents the fatigue limit of the component under the high-low loading sequence, and $\Delta s_{-}$represents the change of the fatigue limit under the high-low loading sequence. $\left(\mathrm{s}_{\mathrm{R}}\right)_{L-H}$ represents the fatigue limit of the component in the high-low loading sequence, and $\Delta s_{+}$represents the change of the fatigue limit in the low-high loading sequence. The magnitude of $\Delta s_{-}$ 
and $\Delta s_{+}$depends on the amplitude and frequency of the maximum stress in the load spectrum of the component.

The fatigue limit under different loading sequence can be expressed by interval variable. Under the high-low loading sequence, the fatigue limit decreases to the lower bound. In the low-high loading sequence, the fatigue limit rises to the upper bound [13], which is:

$\left[\mathrm{S}_{\mathrm{R}}\right]=\left\{\begin{array}{l}{\left[\mathrm{S}_{\mathrm{R}} \stackrel{-}{\longrightarrow}\left(\mathrm{s}_{\mathrm{R}}\right)_{H-L}\right]} \\ \left.\left[\mathrm{S}_{\mathrm{R}}+\mathrm{s}_{\mathrm{R}}\right)_{L-H}\right]\end{array}\right.$

In the equation, $\left(\mathrm{s}_{\mathrm{R}}\right)_{H-L}<\left(\mathrm{s}_{\mathrm{R}}\right)_{L-H}$. The upper and lower limit values of fatigue limit under different loading sequences can be obtained by relevant tests.

The results show that under the action of lowhigh load, the increase of fatigue limit of low carbon steel is as high as $28 \%$, and that of cast iron is $25 \%$.

In the vicinity of fatigue limit $\mathrm{S}_{\mathrm{R}}$, a "fuzzy region" is generated due to different loading sequence.

In this area, the membership function of fuzzy theory will be used to quantify the damage caused by load. If the component bears $m$ different stress levels in service, it is recorded as $S_{i}(i=1,2,3 \ldots \mathrm{m})$.

The number of loading times corresponding to each stress level is recorded as $\mathrm{n}_{i}(i=1,2,3 \ldots l)$.

There are k-level stress levels above the fatigue limit. The number of fatigue failure cycles corresponding to each stress is recorded as $\mathrm{N}_{i}(i=1$, $2,3 \ldots I)$. m-k level is lower than the fatigue limit, and the ultimate fatigue life is $\mathrm{N}_{0}\left(\mathrm{~N}_{0}=10^{7}\right)$. It is assumed that the damage caused by each cyclic load is represented by the fuzzy set $\boldsymbol{B C}^{\mathrm{C}}$, and the damage caused by the stress $S_{i}$ loading once is $B\left(\mathrm{~s}_{\mathrm{i}}\right)$ [14].

If considering the influence of different loading sequence on fatigue limit, different loading sequence will produce a "fuzzy zone" on fatigue limit, and the membership function can be expressed as:

(1) In case of high-low load:

$$
\mu_{B b^{\circ}}\left(\mathrm{s}_{\mathrm{i}}\right)=\left\{\begin{array}{l}
0, s_{i} \geq\left(\mathrm{s}_{\mathrm{R}}\right)_{\mathrm{H}-\mathrm{L}} \\
\mu_{B b^{\circ}}\left(\mathrm{s}_{\mathrm{i}}\right),\left(\mathrm{s}_{\mathrm{R}}\right)_{\mathrm{H}-\mathrm{L}}<s_{i}<s_{R} \\
1, s_{i} \geq s_{R}
\end{array}\right.
$$

(2) In case of low-high load:

$$
\mu_{B b^{6}}\left(\mathrm{~s}_{\mathrm{i}}\right)=\left\{\begin{array}{l}
0, s_{i} \geq \mathrm{s}_{\mathrm{R}} \\
\mu_{B b^{6}}\left(\mathrm{~s}_{\mathrm{i}}\right), s_{R}<s_{i}<\left(\mathrm{s}_{\mathrm{R}}\right)_{L-H} \\
1,\left(\mathrm{~s}_{\mathrm{R}}\right)_{L-H} \leq s_{i}
\end{array}\right.
$$

The defects of the traditional Miner's rule exist errors in life prediction, especially under two-stage load. According to the influence of loading sequence on fatigue limit, it can be modified as follows:

$$
\sum_{i=1}^{k} \frac{n_{1}}{N_{1}}+\sum_{i=k+1}^{m} \mu_{B b^{0}}\left(\mathrm{~s}_{\mathrm{i}}\right) \frac{n_{1}}{N_{1}}=1
$$

Equation 19 is a general expression of fuzzy Miner's law. Considering the S-N curve of probability, the Miner rule of fuzzy probability can be obtained, which can be expressed as follows:

$$
\sum_{i=1}^{k} \frac{n_{i}}{N_{p i}}+\sum_{i=k+1}^{m} \mu_{b^{o}}\left(\mathrm{~s}_{i}\right) \frac{n_{1}}{N_{\mathrm{O} p}}=1
$$

In the equation, $N_{p i}$ is the fatigue failure life with reliability $p$ under the independent action of the i-th level stress. $N_{0 p}$ represents the ultimate fatigue life with a probability of $P$.

\subsection{Determination of membership function}

The change rule of membership degree is called membership function, which refers to the change of membership degree in the middle transition zone from completely available to completely unavailable. The membership functions of different fuzzy conditions should be determined according to the constraint properties and specific application conditions. Objectively speaking, the determination of membership function should be carried out fuzzy statistics, but some artificial skills are allowed. At present, the determination method of membership function is still in the stage of experience. It needs to make use of long-term accumulated practical experience and carry out correction tests continuously to achieve the expected goal. In terms of the selection of membership functions, Huang Hongzhong, Chen Shengjun, Liu kege and others have made relevant research [15].

In the fuzzy assessment and quantification of fatigue damage, the error of fatigue life prediction results is closely related to the selection of membership function. Even for the same membership function, if the parameters of the membership function are different, the prediction results are also different.

Therefore, the choice of membership function and the setting of membership function parameters are very important for the prediction of fatigue life. In the field of mechanical engineering, the membership functions of some incremental heuristics are as follows:

(1) Linear type membership function

$$
\mu_{B B^{3}}\left(\mathrm{~s}_{i}\right)=\left\{\begin{array}{l}
1, s_{i} \geq s_{R} \\
\frac{s_{i}-s_{L}}{s_{-1}-s_{L}}, s_{L}<s_{i}<s_{R} \\
0, s_{i} \leq s_{L}
\end{array}\right.
$$




$$
\mu_{B b^{\circ}}\left(\mathrm{s}_{i}\right)=\left\{\begin{array}{l}
1, s_{i} \geq s_{R} \\
\left(\frac{s_{i}-s_{L}}{s_{R}-s_{L}}\right)^{\frac{1}{2}}, s_{L}<s_{i}<s_{R} \\
0, s_{i} \leq s_{L}
\end{array}\right.
$$

(3) Haibach type membership function

$$
\mu_{B^{\prime}}\left(\mathrm{s}_{i}\right)=\left\{\begin{array}{l}
1, s_{i} \leq s_{L} \\
\left(\frac{s_{i}-s_{L}}{s_{R}-s_{L}}\right)^{2 m-1}, s_{L}<s_{i}<s_{R} \\
0, s_{R} \leq s_{i}
\end{array}\right.
$$

(4) Parabolic type membership function

$$
\mu_{B^{\prime}}\left(\mathrm{s}_{i}\right)=\left\{\begin{array}{l}
1, s_{i} \geq s_{R} \\
\left(\frac{s_{i}-s_{L}}{s_{-1}-s_{L}}\right)^{2}, s_{L}<s_{i}<s_{R} \\
0, s_{i} \leq s_{L}
\end{array}\right.
$$

(5) Normal type membership function

$$
\mu_{D^{6}}\left(\sigma_{i}\right)=\left\{\begin{array}{l}
\exp \left[-\left(\frac{s_{i}-s_{-1}}{s_{c}}\right)^{2}\right], s_{i}<s_{R} \\
1, s_{R} \leq s_{i}
\end{array}\right.
$$

\section{Results \\ 3.1 Comparison results of modified nonlinear models}

Miner's rule of linear cumulative damage, modified nonlinear model, Manson-Halford model and Corten-Dolan model are evaluated and analyzed by using the data of literature.

(1) Two-stage loading

The comparison results of life prediction value and test value under two-stage loading are shown from Figure 3 to Figure 6 (the solid line in the figure is \pm 2 times of its error band). It can be seen from the figure that the predicted results of the improved model are in good agreement with the test values due to the consideration of load sequence and interaction whether under high-low or low-high load. Under high-low load, Miner's life prediction value is more dangerous, while under low-high load, it is the opposite.

The predicted values of Manson-Halford model are conservative under high-low and low-high loads.

When Corten-Dolan model is used to evaluate steel, the predicted values under low-high or highlow loading are all conservative. For lead, the forecast trend is inconsistent. The predicted values of lead 7050 and 2024 are more dangerous than Miner's law. However, in general, under two-stage loading, the revised model has the highest prediction accuracy, followed by Manson-Halford model. If the interaction between loads is very obvious, the accuracy of Corten-Dolan model will be improved.

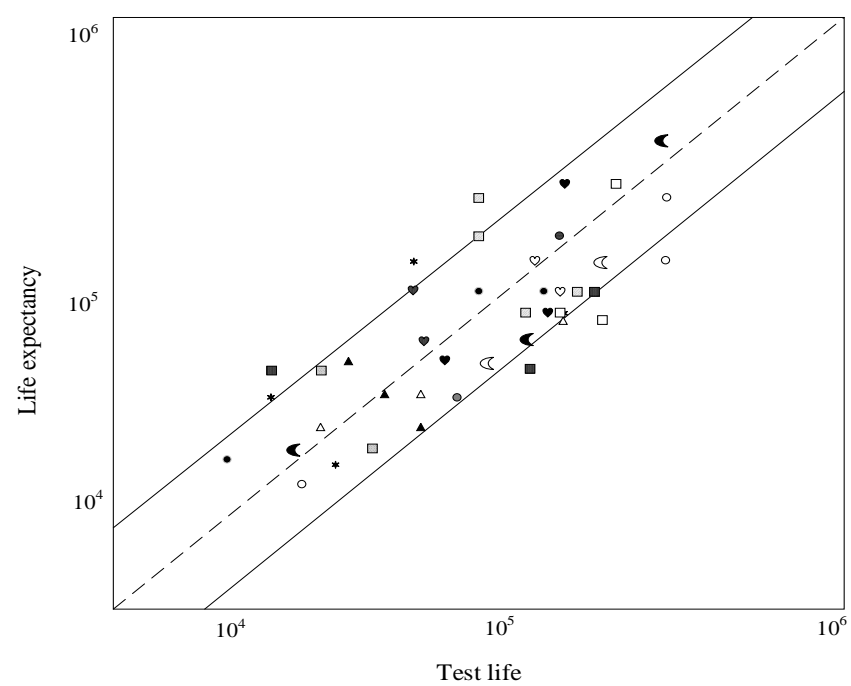

- 45 Miner $\circ 45$ Manson-Halford \16Mn Improved model \ Steel 300CVM Improved mode - 16Mn Manson-Halford $\triangle$ Sled 300CVM Manson-Halford a SAE 4340 Corten-Dolan $\square 45$ Cor \& L6 MnFMiner $16 \mathrm{Mn}$ Corten-Dolan $\odot 45$ improved model $\odot$ Sled 300CVM Corten-Dolan

- SAE 4340 Miner 口 SAE 4340 Manson-Halford a Sled 300CVM Miner * SAE 4340 Improve

Figure 3: Comparison of model predictions and test data for steel under high-low loading 


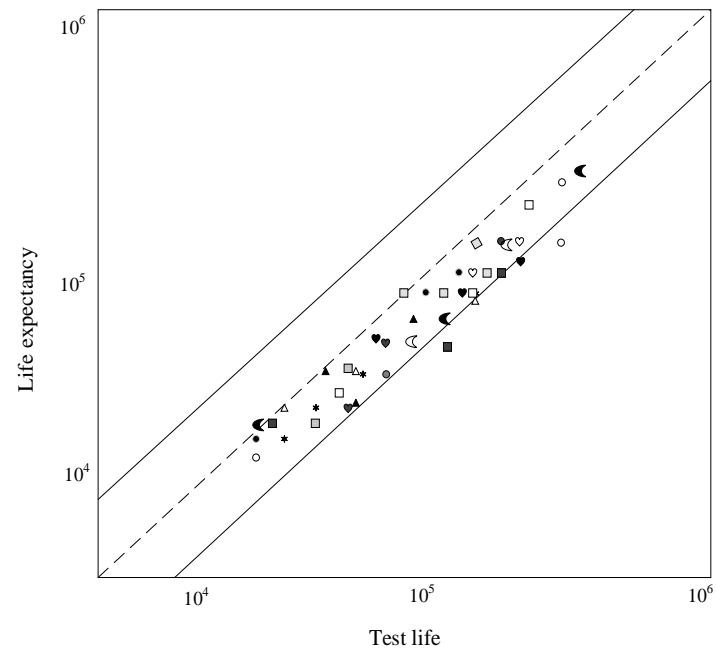

- 45 Miner o 45 Manson-Halford 1 16Mn Improved model \Steel 300CVM Improved model

-16Mn Manson-Halford $\Delta$ Sled 300CVM Manson-Halford a SAE 4340 Corten-Dolan $\quad$ a 45 Cortcn-Dolan

3 L6 MnFMiner 16Mn Cortcn-Dolan $\circ 45$ improved model $\odot$ Sled 300CVM Corten-Dolan

- SAE 4340 Miner $\square$ SAE 4340 Manson-Halford घ Sled 300CVM Miner * SAE 4340 Improved model

Figure 4: Comparison of model predictions and test data for steel under low-high loading

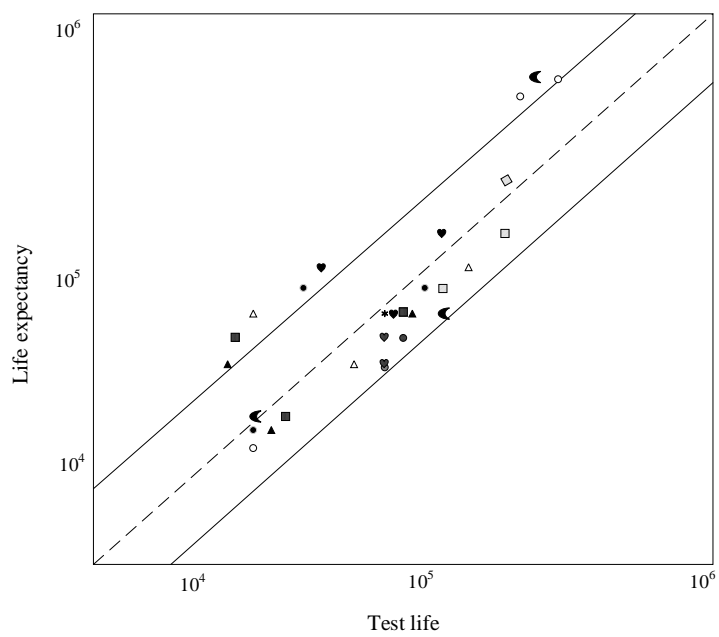

- AL2011 Miner ○ AL2011 Manson-Halford AL2011 Cortcn-Dolan •SAE 4340 Improved model - AL2024 Miner - AL2024 Manson-Halford @ AL2024 Cortcn-Dolan AL2024 Improved model

- AL7050 Miner a AL7050 Manson-Halford $\triangle$ AL7050 Corten-Dolan A AL2011 Improved model

Figure 5: Comparison of model predictions and test data for aluminum under high-low loading

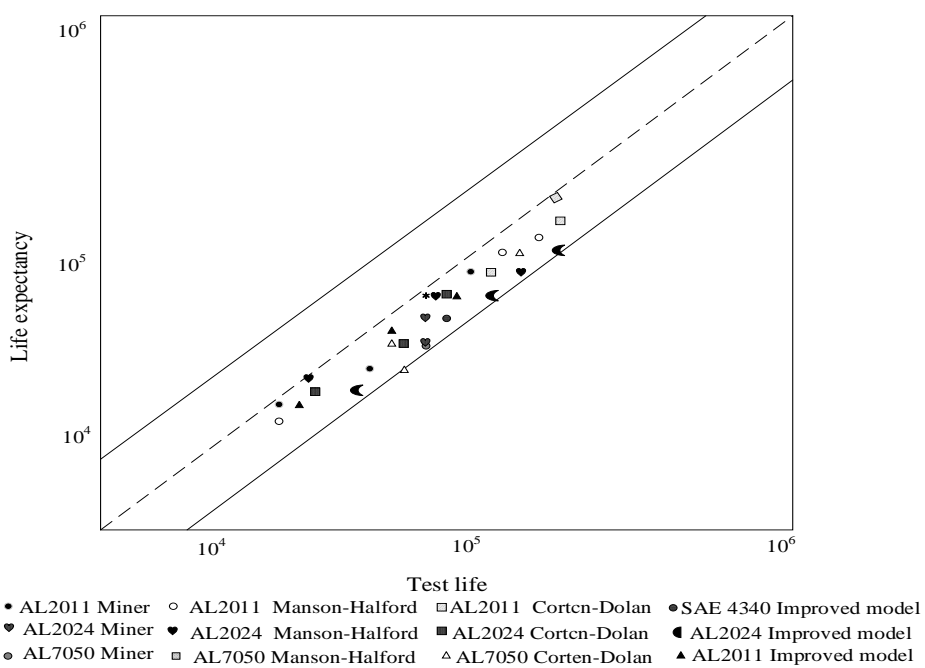

Figure 6: Comparison of model predictions and test data for lead under low-high loading 
(2) Multi-stage loading

The comparison results of life prediction value and test value under multi-stage loading are shown from Figure 7 to Figure 9.

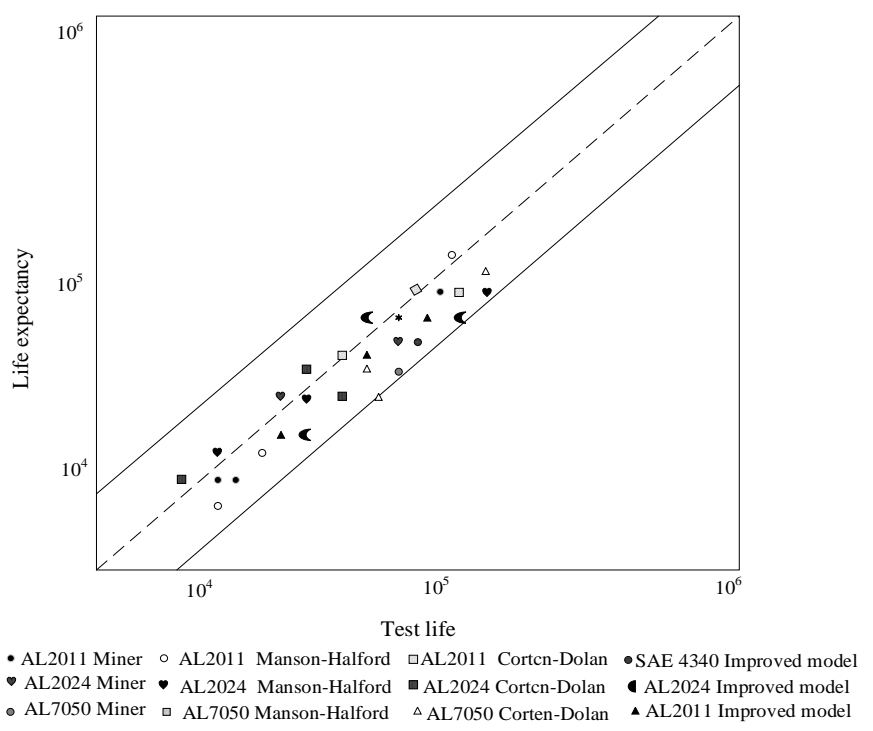

Figure 7: Comparison of model predicted value and test data for aluminum under multi-stage monotonic decreasing loading

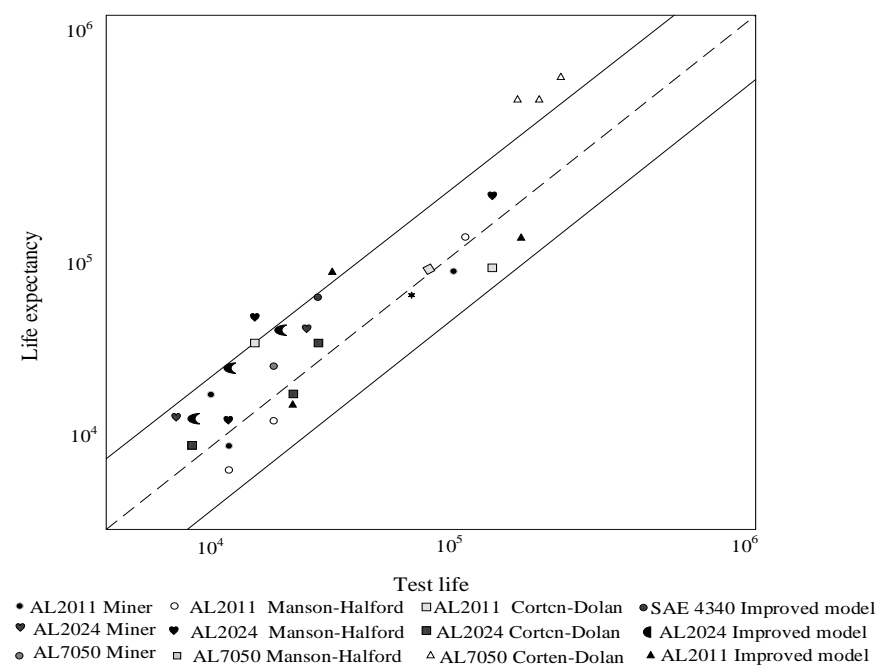

Figure 8: Comparison of model predicted value and test data of aluminum under multi-stage monotonic increasing loading

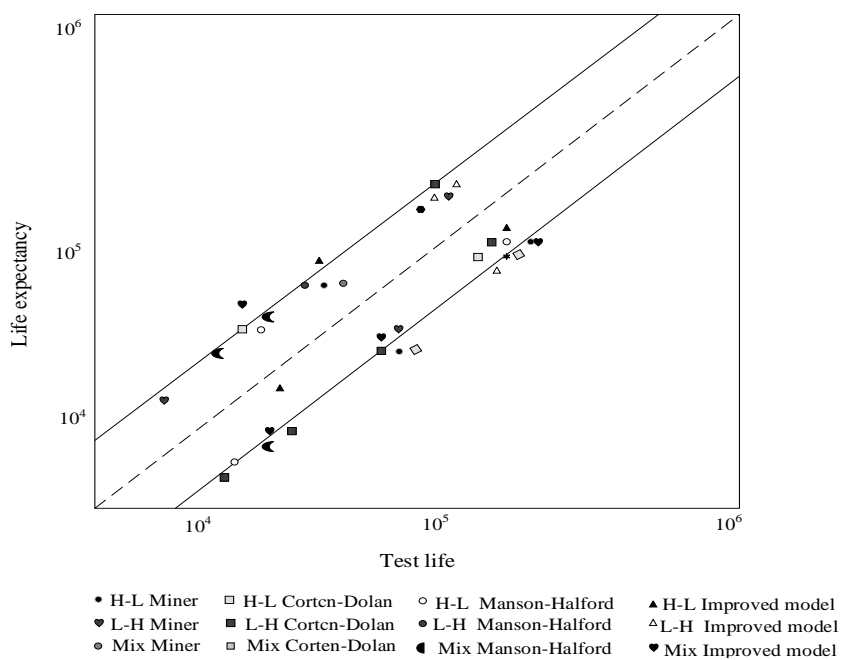

Figure 9: Comparison of model predicted value and test data for steel under multi-stage loading 
It can be seen from Figure 6 to Figure 9 that the prediction results of Corten-Dolan model are poor under monotonic decreasing (H-L) loading, which may be due to the error caused by the selection of index $d$ in Corten-Dolan model. The prediction accuracy of the improved model under multi-stage load is lower than that of the two-stage load.

Compared with the two-stage loading, the life prediction accuracy of Miner's rule is significantly improved, and Manson-Halford model has no obvious advantage when it is compared with Miner's rule.

\section{(3) Random loading}

The comparison results of predicted life value and test value under random loading spectrum are shown in Table 1.

Under the random loading spectrum, no matter the improved model, Manson-Halford model or Miner criterion, the prediction results are not very different. When Corten-Dolan model is used to predict steel, a better precision can be obtained, but the error of lead prediction is large.

Table 1. Predicted value and test value of fatigue life under random loading

\begin{tabular}{|c|c|c|c|c|c|}
\hline Material Science & Miner & Manson-Halford & Corten-Dolan & Improved model & Test value \\
\hline $2024-\mathrm{T} 3$ & 5.5 & 4.32 & 25.39 & 5.22 & 5.97 \\
\hline $2024-\mathrm{T} 3$ & 11.47 & 7.67 & 120.12 & 8.42 & 1.78 \\
\hline $2024-\mathrm{T} 3$ & 18.13 & 17.30 & 9.20 & 16.56 & 9.59 \\
\hline $7075-\mathrm{T} 6$ & 4.47 & 3.45 & 33.00 & 3.32 & 1.78 \\
\hline $7075-\mathrm{T} 6$ & 5.6 & 5.44 & 61.06 & 4.38 & 3.60 \\
\hline $7075-\mathrm{T} 6$ & 5.11 & 4.71 & 206.34 & 3.96 & 12.12 \\
\hline $7075-\mathrm{T} 6$ & 17.99 & 15.23 & 13.73 & 15.42 & 13.20 \\
\hline $7075-\mathrm{T} 6$ & 10 & 9.57 & 23.00 & 10.37 & 20.25 \\
\hline $16 \mathrm{Mn}$ & 3.33 & 3.23 & 2.29 & 3.04 & 3.04 \\
\hline $16 \mathrm{Mn}$ & 95.85 & 94.57 & 75.00 & 97.3 & 138.00 \\
\hline
\end{tabular}

According to the relevant experimental results, according to three classical fatigue damage models and the improved model, for the prediction accuracy and the complexity of the model, it can be obtained that:

(1) Under the condition of two-stage loading, the improved model is in good agreement with the test results because of considering the order of loads and load effects. As for the Manson-Halford model, the loading order between the loads is considered, and the prediction accuracy is relatively good, and the calculation is relatively simple in the two-stage loading prediction, so it is not necessary to determine the model parameters.

The Corten-Dolan model is suitable for two-stage loading because of the interaction between stresses. However, the value of parameter $d$ is quite difficult, especially for different load spectrum and materials.

(2) Under multi-stage loading, the improved model and Manson-Halford model need constant iterative calculation, which has large amount of calculation, while the linear Miner method is easy to calculate. Compared with Miner's rule, the improved model and Manson-Halford model do not improve the accuracy much, while the prediction accuracy of Corten-Dolan model is relatively poor due to the selection of index $\mathrm{d}$.

(3) Under the action of random loading, the calculation process of the improved model, CortenDolan model and Manson-Halford model is complex.

The calculation of Miner's law is relatively simple and convenient, and the accuracy is not very poor compared with the complex nonlinear model.
In the actual engineering structure, the load borne by members is basically random loading.

According to the treatment of load spectrum by rain flow counting method, Manson-Halford model and Corten-Dolan model also cannot reflect the consideration of the load sequence and load interaction for the magnitude of peak valley value and the randomness of order of load spectrum, and do not fundamentally avoid the defects of Miner's law.

\subsection{Accuracy comparison results of membership function model}

In order to verify the accuracy of the model, in this study, combined with an example, the test data of $40 \mathrm{Cr}$ and $16 \mathrm{Mn}$ alloy steel materials for common gears are used to verify the model from two aspects of loading sequence: high-low and low-high.

(1) Loading test under high-low load sequence

The standard smooth sample used in the calculation example is shown in Figure 10.



Figure 10: Smooth cantilever bend specimen 
The material is $40 \mathrm{Cr}$, static strength $\sigma_{b}=850 \sim$ $900 \mathrm{MPa}$, loading mode is cyclic bending, average stress $\mathrm{S}_{m}=0$, and stress cyclic characteristic $\mathrm{R}=1$.

The test piece is loaded according to the 8-stage cyclic stress given in Table 2. $n_{i}$ is the frequency of stress loading at all levels, and the fatigue life of the tested material is $2.2 \times 10^{7}$. In the table, the value of $N_{i}$ is the fatigue life of the specimen under different stress levels $S_{i}$, which can be obtained from the S-N curve.
By using the linear Miner fatigue cumulative damage rule, it can be obtained that:

$$
N_{f p}=\frac{\sum n_{i}}{\sum\left(n_{i} / N_{i}\right)}=3.554 \times 10^{7}
$$

The estimated error is:

$$
\varepsilon=\frac{N_{f p}-N_{0}}{N_{f p}}=61.57 \%
$$

Obviously, the influence of loading sequence on fatigue damage is not considered in the above estimation results, so the error is large.

Table 2. Data of multi-stage stress loading test

\begin{tabular}{|c|c|c|c|c|}
\hline $\begin{array}{c}\text { Stress } \\
\text { progression }\end{array}$ & $\sigma_{i} /(\mathrm{MPa})$ & $n_{i}$ & $N_{i}$ & $n_{i} / N_{i}$ \\
\hline 1 & 350 & 44 & $5.6 \times 10^{4}$ & 0.0008 \\
\hline 2 & 332 & 352 & $7.4 \times 10^{4}$ & 0.047 \\
\hline 3 & 298 & 6160 & $1.3 \times 10^{5}$ & 0.0475 \\
\hline 4 & 254 & 59840 & $2.8 \times 10^{5}$ & 0.2140 \\
\hline 5 & 201 & 440000 & $1.25 \times 10^{5}$ & 0.3520 \\
\hline 6 & 194 & 2024000 & $\rightarrow \infty$ & 0 \\
\hline 7 & 96 & 6160000 & $\rightarrow \infty$ & 0 \\
\hline 8 & 44 & 13310000 & $\rightarrow \infty$ & 0 \\
\hline
\end{tabular}

According to the equation 15 fuzzy Miner rule, considering the influence of high-low load sequence on fatigue limit, a "fuzzy interval" is extended on the left side of the original fatigue limit ${ }^{S_{-1}}$.

$\left(\mathrm{s}_{-1}\right)_{H-L}=(0.82-0.9) \mathrm{S}_{\mathrm{R}}$ is measured by twostage loading fatigue test.
In order to better compare the different types of membership function to estimate the fatigue life of components, the nonlinear fatigue damage models (the revised model, Manson-Halford model and Corten-Dolan model proposed in the above content) are used to estimate the fatigue life of components.

The calculation results are shown in Table 3.

\begin{tabular}{|c|c|c|c|c|c|}
\hline & \multicolumn{2}{|c|}{ Fatigue cumulative damage model } & $\mathrm{D}$ & $N_{f p} / 10^{7}$ & Error $\delta / \%$ \\
\hline 1 & \multicolumn{2}{|c|}{ Tradition Miner } & 0.619 & 3.549 & 61.57 \\
\hline 2 & \multicolumn{2}{|c|}{ Revised model } & 1.083 & 2.03 & 24.24 \\
\hline 3 & \multicolumn{2}{|c|}{ Manson-Halford } & 1.157 & 1.87 & 27.6 \\
\hline 4 & \multicolumn{2}{|c|}{ Corten-Dolan } & 1.36 & 1.79 & 31.9 \\
\hline 5 & \multirow{6}{*}{$\begin{array}{c}\text { Types of } \\
\text { membership } \\
\text { functions }\end{array}$} & Linear type & 0.808 & 2.72 & 19.11 \\
\hline 6 & & Parabolic type & 1.128 & 2.17995 & 11.34 \\
\hline 7 & & $\begin{array}{c}\text { Square root } \\
\text { type }\end{array}$ & 1.103 & 1.92191 & 10.32 \\
\hline 8 & & Haihach & 0604 & 295752 & 306 \\
\hline 9 & & Па⿴囗口асп & 0.094 & $2.95 / 52$ & 30.0 \\
\hline 10 & & Normal form & 0.785 & 2.8025 & 21.5 \\
\hline
\end{tabular}

Table 3. Life prediction results of multi-stage stress loading (H-L) with different membership functions

(2) Loading test under low-high load sequence

Three groups of experimental data of two-stage stress loading in low-high load sequence of $16 \mathrm{Mn}$ steel bar smooth test-piece are taken as examples. The first level load $s_{1}$ acts on $n_{2}$, and then the second level load $s_{2}$ acts until fatigue failure occurs in the test-piece $\left(\mathrm{s}_{1}<\mathrm{s}_{2}\right)$.
The fatigue limit of the test piece is $S_{-1}=$ $370.8 \mathrm{Mpa}$, the test parameter $m=2.3, \mathrm{~N}_{0}=5 \times 10^{5}$ times. Test parameters and data are shown in Table 4. In the low-high loading tests I, II and III, the strengthening coefficient measured from fatigue test is $\mathrm{m}^{\prime}=6.25043 \times 10^{8}$, and the lower bound of strengthening load is $\mathrm{s}_{\mathrm{L}}=342.8 \mathrm{MPa}$. 
The fatigue limit under low-high FF loading sequence is $\left(\mathrm{s}_{-1}\right)_{H-L}=(1.15 \sim 0.9)^{\mathrm{S}_{-1}}$. Using the fuzzy Miner rule and the revised model, the life of the specimen is predicted.

The comparison of the results is shown in Tables 5,6 and 7.

Table 4. Test data of $16 M n$ steel under low-high loading sequence

\begin{tabular}{|c|c|c|c|c|c|}
\hline \multirow{3}{*}{ Test number } & $\begin{array}{c}\text { Stress } \\
\text { progression }\end{array}$ & $\begin{array}{c}\text { Stress } \\
\text { amplitude } \sigma_{i} /(\mathrm{MPa})\end{array}$ & $n_{i}$ & $N_{i}$ & $n_{i} / N_{i}$ \\
\hline \multirow{2}{*}{ I } & 1 & 392.3 & 224123 & 400220 & 0.56 \\
\cline { 2 - 6 } & 2 & 562.9 & 57950 & 93500 & 0.62 \\
\hline \multirow{2}{*}{ II } & 1 & 372.65 & 351725 & 470300 & 0.75 \\
\cline { 2 - 6 } & 2 & 392.3 & 16892 & 400220 & 0.52 \\
\hline \multirow{2}{*}{ III } & 1 & 372.65 & 178714 & 470300 & 0.38 \\
\cline { 2 - 6 } & 2 & 562.9 & 71600 & 93500 & 0.76 \\
\hline
\end{tabular}

Table 5. Test I Comparison of predicted life and test results of different membership functions of 16Mn under

\begin{tabular}{|c|c|c|c|c|c|c|}
\hline & \multicolumn{2}{|c|}{ Fatigue cumulative damage model } & $\begin{array}{c}\text { Loading } \\
\text { order }\end{array}$ & $\mathrm{D}$ & $N_{f p} / 10^{6}$ & $\begin{array}{l}\text { Error } \\
\delta / \%\end{array}$ \\
\hline 1 & \multicolumn{2}{|c|}{ Tradition Miner } & \multirow{7}{*}{$\mathrm{L}-\mathrm{H}$} & 1.18 & 2.71 & 42.5 \\
\hline 2 & \multicolumn{2}{|c|}{ Revised model } & & 1.02 & 2.26 & 10.09 \\
\hline 3 & \multirow{5}{*}{$\begin{array}{l}\text { Types of } \\
\text { membership } \\
\text { functions }\end{array}$} & Linear type & & 0.96 & 2.14 & 13.46 \\
\hline 4 & & Parabolic type & & 1.12 & 2.43 & 9.33 \\
\hline 5 & & Square root type & & 1.003 & 2.75 & 10.42 \\
\hline 6 & & Haibach & & 0.842 & 3.44 & 21.4 \\
\hline 7 & & Normal form & & 0.779 & 3.62 & 32.4 \\
\hline
\end{tabular}

Table 6. Test II Comparison of life prediction and test results of 16Mn under different membership functions in

\begin{tabular}{|c|c|c|c|c|c|c|}
\hline & & & & & low-high I & geque \\
\hline & \multicolumn{2}{|c|}{ Fatigue cumulative damage model } & $\begin{array}{l}\text { Loading } \\
\text { order }\end{array}$ & $\mathrm{D}$ & $N_{f p} / 10^{6}$ & $\begin{array}{l}\text { Error } \\
\delta / \%\end{array}$ \\
\hline 1 & \multicolumn{2}{|c|}{ Tradition Miner } & \multirow{7}{*}{$\mathrm{L}-\mathrm{H}$} & 1.28 & 2.93 & 31.75 \\
\hline 2 & \multicolumn{2}{|c|}{ Revised model } & & 1.072 & 2.63 & 9.09 \\
\hline 3 & \multirow{5}{*}{$\begin{array}{c}\text { Types of } \\
\text { membership } \\
\text { functions }\end{array}$} & Linear type & & 0.941 & 2.51 & 14.8 \\
\hline 4 & & Parabolic type & & 0.974 & 2.58 & 9.33 \\
\hline 5 & & Square root type & & 1.041 & 2.75 & 10.93 \\
\hline 6 & & Haibach & & 0.894 & 3.25 & 19.90 \\
\hline 7 & & Normal form & & 0.812 & 3.46 & 26.35 \\
\hline
\end{tabular}

Table 7. Test III Comparison of life prediction and test results of 16Mn under different membership functions in

\begin{tabular}{|c|c|c|c|c|c|c|}
\hline & & & & & \multicolumn{2}{|c|}{ low-high loading sequenc } \\
\hline & \multicolumn{2}{|c|}{ Fatigue cumulative damage model } & $\begin{array}{c}\text { Loading } \\
\text { order }\end{array}$ & D & $N_{f p / 10^{6}}$ & $\begin{array}{l}\text { Error } \\
\delta / \%\end{array}$ \\
\hline 1 & \multicolumn{2}{|c|}{ Tradition Miner } & \multirow{7}{*}{$\mathrm{L}-\mathrm{H}$} & 1.14 & 2.13 & 41.25 \\
\hline 2 & \multicolumn{2}{|c|}{ Revised model } & & 1.003 & 2.43 & 10.09 \\
\hline 3 & \multirow{5}{*}{$\begin{array}{c}\text { Types of } \\
\text { membership } \\
\text { functions }\end{array}$} & Linear type & & 0.894 & 2.28 & 14.3 \\
\hline 4 & & Parabolic type & & 0.936 & 2.228 & 9.78 \\
\hline 5 & & Square root type & & 1.035 & 2.125 & 12.43 \\
\hline 6 & & Haibach & & 0.836 & 2.83 & 17.90 \\
\hline 7 & & Normal form & & 0.719 & 2.972 & 38.35 \\
\hline
\end{tabular}




\section{Discussion}

In this study, firstly, an improved nonlinear fatigue damage accumulation model is proposed, that is, the damage curve method proposed by Manson-Halford is improved by introducing the damage parameters controlled by stress and considering the interaction between loads.

The improved nonlinear fatigue damage accumulation model can not only consider the interaction between loads, but also consider the order effect of loads, which improves the traditional damage curve method and makes it more reasonable to consider the actual damage problem.

Then, through the evaluation of four models under the action of two-stage load, multi-stage load and random load, it is found that due to the complexity of the modified model, the prediction results under random load are not very ideal. In terms of the accuracy and complexity of the model, the linear cumulative damage theory (Miner rule) should be widely used in engineering because of its simplicity and convenience. Under the action of multi-stage random load, the prediction accuracy obtained by the nonlinear theory with complex model is not much higher than it.

At the same time, with the continuous development of science and technology, the working environment of the structure and its service load are more stringent. In the fatigue life prediction, the uncertainty factors such as material, load, structure layout and manufacturing process, are more and more important.

Due to its own defects, deterministic fatigue life prediction cannot be included in the influence of uncertainty factors, which leads to the large error of life prediction value and cannot meet the actual demand.

Therefore, aiming at the defects of Miner model, in this study, the fuzzy theory is used to consider the uncertainty of fatigue damage, and the fuzziness of fatigue damage under different load sequence is quantitatively described.

Through the specific test data, it is proved that the method is correct and practical to improve the prediction ability of fatigue life. Through the analysis of alloy steel for gear, the prediction error of the modified miner model is about $10 \%$, while the parabola membership function error of the membership function is reduced to about $9 \%$. The results show the feasibility and accuracy of the proposed model and method.

Although the error of the fuzzy Miner rule has been obviously reduced, there are still some errors in the experimental results.
Therefore, in practical application, the error of the predicted value should be fully considered, so as to avoid huge loss to the mechanical structure. At the same time, it is necessary to further study the proposed model, continue to reduce the error of prediction value, and improve the accuracy of the model.

\section{Conclusions}

It can be seen from the experimental prediction results that compared with the traditional Miner rule, the error between the predicted part life and the experimental value of the revised Miner rule is significantly reduced, and the error of the fuzzy Miner rule determined by the parabolic membership function is further reduced, which shows the feasibility of the fuzzy Miner rule of the membership function.

From the overall effect of the experimental results, the error of fuzzy Miner's law of parabola membership function is the smallest, which further proves the feasibility and excellence of the proposed modified model and fuzzy Miner's law.

\section{References}

[1] Wu X. Z., Lin B., Cheng J. S, et al. (2017) Cracked Steel Plates Repaired by Stop Holes and CFRP and Fatigue Life Prediction. Journal of Tianjin University, 50(2), 154-158.

[2] Chen L., Zhang X. M., Liu F, et al. (2017) Discussion of Low Cycle Fatigue Life Prediction Models for Magnesium Alloys. China Mechanical Engineering, 28(5), 512-518.

[3] Li F. P. (2019) Research on Drill Pipe's Fatigue Life Prediction Based on Reliability. Materials Science Forum, 944, 975-980.

[4] Zheng B., Yu H. D., Lai X. M, et al. (2016) Analysis of Residual Stresses Induced by Riveting Process and Fatigue Life Prediction. Journal of Aircraft, 53(5), 1-8.

[5] Skibicki D., Pejkowski Ł. (2017) Low-cycle multiaxial fatigue behaviour and fatigue life prediction for CuZn37 brass using the stressstrain models. International Journal of Fatigue, 102, 18-36.

[6] Sun L. L., Zhang M., Hu W. P, et al. (2016) Tension-Torsion High-Cycle Fatigue Life Prediction of 2A12-T4 Aluminium Alloy by Considering the Anisotropic Damage: Model, Parameter Identification, and Numerical Implementation. Acta Mechanica Solida Sinica, 29(4), 391-406.

[7] Tang H. S., Mei J. H., Chen W, et al. (2016) Uncertainty Analysis in Fatigue Life Prediction 
of Concrete Using Evidence Theory. Materials Science Forum, 866, 25-30.

[8] Alma H. (2016) Fatigue Life Prediction of Composites and Composite Structures Edited by VassilopoulosA. P Woodhead Publishing, Abington Hall, Granta Park, Great Abington, Cambridge, CB21 6AH, UK. 2010. 552pp. Illustrated. $£ 159$. ISBN 978-1-4398-2789-5. 118(1202), 452-453.

[9] Chen X. D., Dong L., Kang Y. J, et al. (2017) The Max-Min Cycle Counting Method for Fatigue Life Prediction under Non-proportional Loading. Reneng Dongli Gongcheng/Journal of Engineering for Thermal Energy and Power, 32(8), 130-137.

[10] Jin D., Gou Z. F. (2017) A New Method of Fatigue Life Prediction for Notched Specimen. Journal of Aeronautical Materials, 37(2), 81-87.

[11] Yue P., Lei Q., Zhang C. L, et al. (2016) A Modified Cumulative Damage Model for Fatigue Life Prediction under Variable Amplitude
Loadings. Applied Mechanics \& Materials, 853, 62-66.

[12] Jin Z., He L., Zhao Y. L. (2017) Fatigue Life Prediction of Rubber Isolator Based on ForceControlled Temperature-Accelerated Fatigue Experiment. Journal of Failure Analysis \& Prevention, 17(7), 1-6.

[13] Wang K., Xie X. B., Li Y. Z, et al. (2018) Prediction Method of the Dwell-Fatigue Life for Titanium AlloysTi-6Al-4V at Room Temperature. Ship Building of China, 59(2), 123-128.

[14] Zhu S. P., Huang H. Z., Peng W, et al. (2016) Probabilistic Physics of Failure-based framework for fatigue life prediction of aircraft gas turbine discs under uncertainty. Reliability Engineering System Safety, 146, 1-12.

[15] Zhou J., Huang H. Z., Peng Z. C. (2017) Fatigue life prediction of turbine blades based on a modified equivalent strain model. Journal of Mechanical Science \& Technology, 31(9), 42034213. 